\title{
Virtual Environment in Construction and Maintenance of Buildings
}

\author{
A.Z. Sampaio ${ }^{1}$, A.R. Gomes, A. M. Gomes, J. P. Santos and D. Rosário \\ Technical University of Lisbon, Department of Civil Engineering and Architecture, Lisbon, Portugal
}

\begin{abstract}
This paper describes two prototype applications based on Virtual Reality (VR) technology for use in construction and maintenance planning of buildings. The first, applied to construction, is an interactive virtual model designed to present plans three-dimensionally (3D), connecting them to construction planning schedules, resulting in a valuable asset to the monitoring of the development of construction activity. The $4 \mathrm{D}$ application considers the time factor showing the 3D geometry of the different steps of the construction activity, according to the plan established for the construction. A second VR model was created in order to help in the maintenance of exterior closures of walls in a building. It allows the visual and interactive transmission of information related to the physical behavior of the elements. To this end, the basic knowledge of material most often used in façades, anomaly surveillance, techniques of rehabilitation, and inspection planning were studied. This information was included in a database that supports the periodic inspection needed in a program of preventive maintenance. This work brings an innovative contribution to the field of construction and maintenance supported by emergenttechnology.
\end{abstract}

Index Terms-Construction; Maintenance; Virtual Reality;Interactive model.

\section{INTRODUCTION}

The main aim of a research project, now in progress at the Department of Civil Engineering of the Technical University of Lisbon, is to develop virtual models as tools to support decision-making in the planning of construction management and maintenance, PTDC/ ECM/67748/ 2006, "Virtual Reality technology applied as a support tool to the planning of construction maintenance". A first prototype for the lighting system had already been completed [1]. A second prototype concerning construction planning is now complete [2] and the VR model concerning maintenance of the closure of exterior walls is also finished [3] [4]. Another VR models, now in progress, will support the inspection activity of two other components of a building: the surface of floors and the roof. This paper describes these two later concluded models created as part of the
Manuscript Received on September 1, 2011

1'E-mail: zita@civil.ist.utl.pt

overall research project.

These interactive models integrate Virtual Reality (VR) technology and applications implemented in Visual Basic (VB) language. The models allow interaction with the $3 \mathrm{D}$ geometric model of a building, visualizing components for eachconstruction. They are linked to databases of the corresponding technical information concerning construction planning and the maintenance of the materials used as exterior closures. The principal objective of the interactive VR prototypes is to support decision-making in the area of planning.

Information technology, namely 4D modeling (3D+time) and VR techniques is currently in use both in the construction activity and in education [5]. At the Department of Civil Engineering, some didactic models have already been generated. The research project presented in this paper follows on from that previous educational work: two 3D geometricmodels which support activity in the rehabilitation of buildings [6]; and three VR models developed to support classes in Civil Engineering (wall, bridge and roof construction) in Technical Drawing, Construction and Bridge disciplines [7]. The didactic VR models are in common use in both face-to-face classes and on an e-learning platform.

Virtual Reality technology can support the management of data that is normally generated and transformed or replaced throughout the lifecycle of a building. This technology constitutes an important support in the management of buildings allowing interaction and data visualization. At present, the management of building planning can be presented in 3D form and various materials can be assigned to the fixtures and furnishing enabling the user to be placed in the virtual building and view it from inside as well as outside. This study contemplates

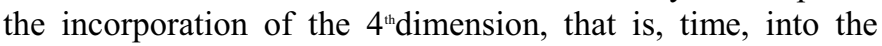
concept of visualization. The focus of the work is on travelling through time, or the ability to view a product or its components at different points in time throughout their life. In maintenance, the time variable is related to the progressive deterioration of the materials throughout the building's lifecycle. It is implicit that the incorporation of the time dimension into $3 \mathrm{D}$ visualization will enable the designer/user to make more objective decisions about the choice of the constituent components of the building.

In construction industry, from the conception to the actual implementation, project designs are presented mostly on paper, even though the two dimensional reading is often not enough, 
as mistakes can be introduced in early stages of conception or elements misunderstood on the construction site. 3D models present an alternative to avoid inaccuracies, as all the information can be included with the necessary detail. Computer systems used in construction for graphic representation have experienced a vast evolution, allowing new ways of creating and presenting projects. 4D models, also labelled as 3D evolutionary models, permit a better comprehension of the project throughout its life, minimizing the information loss through the chain of events. In addition VR technology can present a step-by-step guide in assembling complex structures in an interactive way. One of the benefits of VR in construction is the possibility of a virtual scenario being visited by the different specialists, exchanging ideas and correcting mistakes. Some applications are already offering the possibility of communication between different specialties while developing a mutual project [8].

In construction management, over the years, technical drawings have played a crucial role in communication between the numerous partners in a project. Generally, drawings represent formal solutions, and often incompatibility mistakes are only detected at advanced stages, on site, accruing additional costs. In this field 4D models promote the interaction between the geometric model and construction activity planning, allowing immediate perception of the evolution of the work. In planning, in correct evaluation and the meeting ofneeds as they arise, 4D models constitute a positive contribution to decision-making when establishing planning strategies [9].

Section 2 describes the maintenance model, highlighting theconstitution of the database supporting the model, and the organization of a user-friendly interface designed to be used by an inspection worker. During the construction of this model, the basic knowledge of the topics involved, such as aspects related to the materials, the techniques of rehabilitation and conservation and the planning of maintenance is outlined and discussed. In addition, methods of interconnecting this knowledge with the virtual model are explored. This prototype was trialed in an actual project. Section 3 concerns the interior walls (Fig. 1).

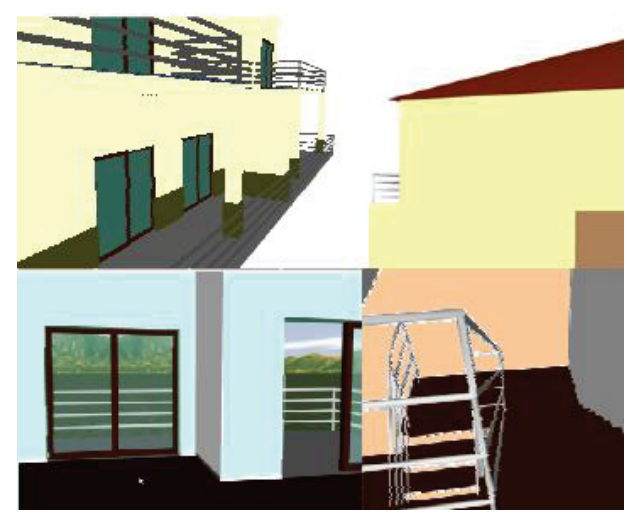

Fig. 1. 3D model of the house: coating elements of exterior and interior walls.

These aspects of the construction activity are in constant evolution, so require the study of preventive maintenance, though, for example, the planning of periodic local inspections and corrective maintenance with repair activity analysis. For this reason, the VR models facilitative the visual and interactive access to results, supporting the drawing-up of inspection reports.

The construction model, presented in Section 4, brings an innovative aspect to 4D modeling as usually applied to construction planning, through the incorporation of pictures into the interface of the VR model, an important support element in the comparison between what is planned and what is in progress in situ after each construction task.

\section{THE FAÇADES MAINTENANCE MODEL}

The maintenance of walls prototype incorporates interactive techniques and input devices to perform visual explorationtasks. To support this system a data base was created whichincluded a bibliographic research support made in regard to theclosure materials used in the exterior walls of a building,anomalies concerning different kinds of covering material, andcorrective maintenance. Repair activities were also studied. Theprogramming skills of those involved in the project had to beenhanced so that they could achieve the integration of thedifferent kinds of data bases needed in the creation of theinteractive model.

Façade coatings play an important role in the durability of buildings, since they constitute the exterior layer that ensuresthe protection of the wall against the aggressive actions of aphysical, chemical or biological nature. Naturally, they shouldalso give the façade the required decorative effect. Since thisbuilding component is exposed to adverse atmosphericconditions it frequently shows an evident degree ofdeterioration, requiring maintenance work. In order to arrive atthe best solution for eventual maintenance and repair work, asurvey of defects and deterioration must be conducted.

\subsection{Characteristics of the materials used in façades}

In order to better understand the operation of façade coating,bibliographic research of materials usually applied to this typeof material was carried out and a table of characteristics of thesewas drawn up. Subsequently, a survey was made of anomalies,probable causes, solutions and methods of repair for each of thecoatings studied. The visualization of the maintenance data of abuilding and the impact of time on the performance of theseexterior closure materials require an understanding of theircharacteristics [10] (Fig. 2):

- $\quad$ Types of material: painted surfaces, natural stone panelsand ceramic wall tiles;

- Application processes: stones (panel, support devices, adherent products, etc.); ceramic tiles (fixed mechanism,procedures, ...); painted surfaces (types of paint products,prime and paint scheme surface, exterior emulsion paints,application processes); 
- Anomalies: dust and dirt, lasting lotus leaf effect, covering power, insufficient resistance to air permeability orweather-proof isolation, damaged stones or ceramic tiles,alkali and smear effect, efflorescence, fractures and fissuresand so on;

- Repair work: surface cleaning, wire truss reinforcing,cleaning and pointing of stonework joints, removing andreplacement of ceramic wall tiles, removing damaged paintand paint surface, preparing and refinishing stone panels, etc..

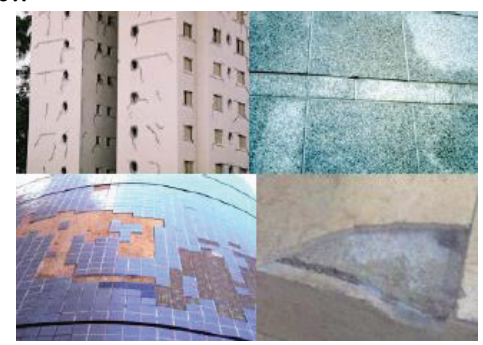

Fig. 2. Different types of materials applied as façade coatings presentinganomalies.

Depending on the role that the façade coatings play on the wall as a whole they can be classified as finishing, sealing or thermal insulation. The most frequent materials used as coating finishes are painting, tiling and, as sealing coating of the natural stone:

- Paint coating contributes to the aesthetic quality of the building and its environment and also protects the surface of the exterior wall against corrosion, deterioration and penetration of aggressive agents [11];

- The ceramic coating consists essentially of tiling panels, cement and adhesive and the joints between the slabs. The application of ceramic tiling to building façades has considerable advantages particularly as some degree of waterproofing is afforded by the glazed surface along with a great resistance to acids, alkalis and vapor [12];

- The use of natural stone in the coating of façade surfaces is a good solution both technically and aesthetically. The principal characteristics of the stones are: reduced water absorption, sufficient mechanical resistance to bending and impact, abrasion and shearing parallel to the face of the slabs.

\subsection{The database}

The most frequent anomalies that occur in the coated façades were analyzed in order to create a database linked to the virtual model that could support the planning of inspections and maintenance strategies in buildings. This database contains the identification of anomalies that can be found in each type of material used in façades and the corresponding probable cause. For each type of anomaly the most adequate repair solutions were also selected and included in the database. The following example, concerning deficiencies in tiles, illustrates the methodology implemented in this virtual application (Table 1).

The 3D virtual model can be seen, therefore, as an important tool for anomaly surveillance in structures and for supporting decision-making based on the visual analysis of alternative repair solutions. The model can be used by any partner in any work.

\subsection{The interface}

The implementation of the prototype system makes use of graphical software programming, Microsoft Visual Basic 6.0, software to establish a suitable database, Microsoft officeaccess, graphical drawing system, AutoCAD Autodesk and VR technology based software, EON Studio [13].

Many potential users are not computer experts. Human perceptual and cognitive capabilities, therefore, were taken into account when designing this visualization tool with the result that the model is easy to use and does not require sophisticated computer skills. It uses an interactive $3 \mathrm{D}$ visualization system based on the selection of elements directly within the virtual 3D world. Furthermore, associated with each component, there are integrated databases, allowing the consultation of the required data at any point in time.

TABLE 1. EXAMPLE OF ANOMALIES AND THE ASSOCIATED REPAIR SOLUTION

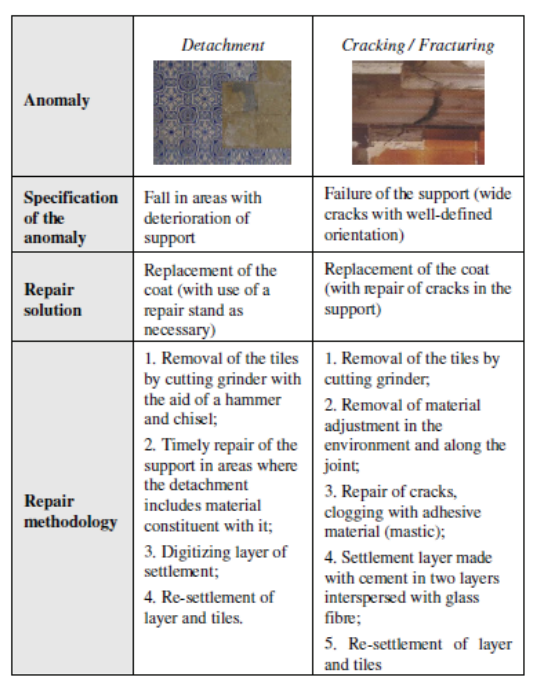

The interface is composed of a display window allowing users to interact with the virtual model, and a set of buttons for inputting data and displaying results (Fig. 3). For each new building to be monitored, the characteristics of the environment (exposure to rain and sea) and the identification of each element of the façades must be defined. The data associated to each element are the building orientation, the type of exterior wall (double or single), and the area and type of coating.

Once each monitored element has been characterized, various inspection reports can be defined and recorded and thereafter consulted when needed. An inspection sheet is accessed from the main interface (Fig. 4). 
The inspection sheet includes the type of covering (natural stone, Fig. 5), the anomalies (Cracking /Fracturing) and a list ofpossible causes to be selected and associated to the element.Several photos can be added (Fig. 4).

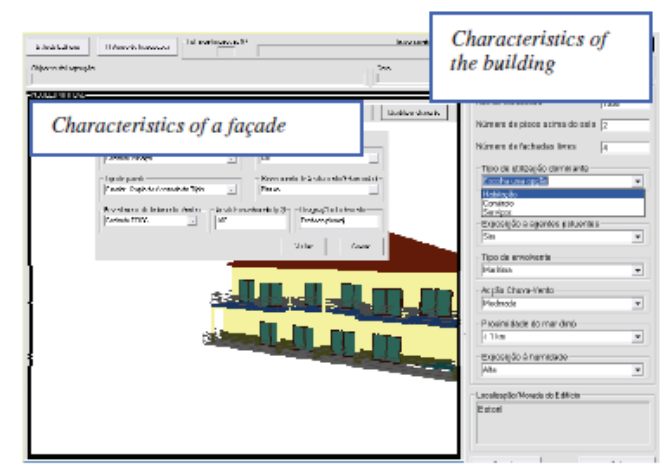

Fig. 3. The main interface of the interactive application.

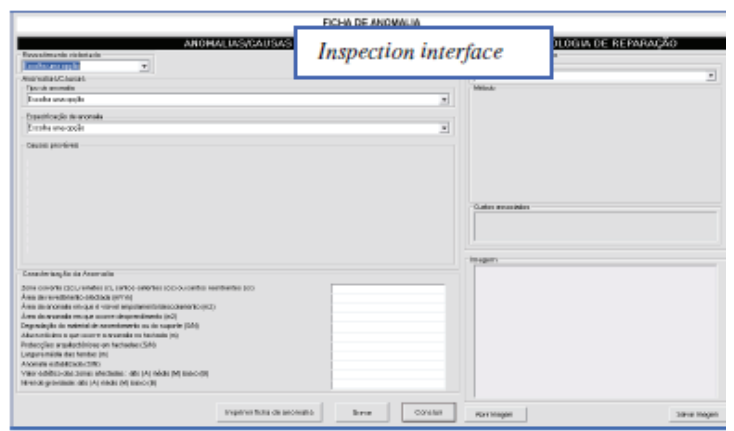

Fig. 4. Inspection sheet interface

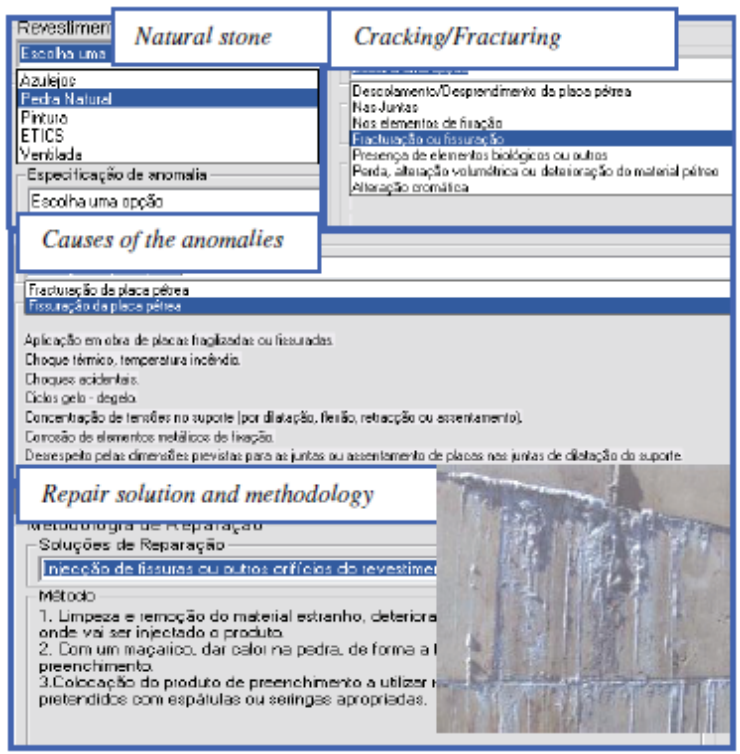

Fig. 5. Selecting data in the inspection interface

The repair solution and methodology associated to the selected type of anomaly is also presented (Fig. 5). These data are then linked to the element. A report history of inspections is permanently associated to the building so that during any later interaction with the model, the inspection report that was defined using the prototype can be accessed.
To sum up, by using the drop-down menus allowed by the interface, the user can associate the characteristics of the observed anomaly to: a façade element; the type of anomaly, the specification, details and the probable cause of the anomaly, an adequate repair solution and pictures taken in the building. After completing all fields relating to an anomaly, the user can present the report as a $p d f f i l e$.

\subsection{The case study}

First, the 3D geometric model of a building was created (Fig. 6). In this case, the building consists of a ground-floor, a 1sfloor and an attic with dwelling space. The coating elements of the walls were then modeled as independent geometric objects. In this way, each element can then support characterization data of the applied material and different kinds of information relatedto maintenance.
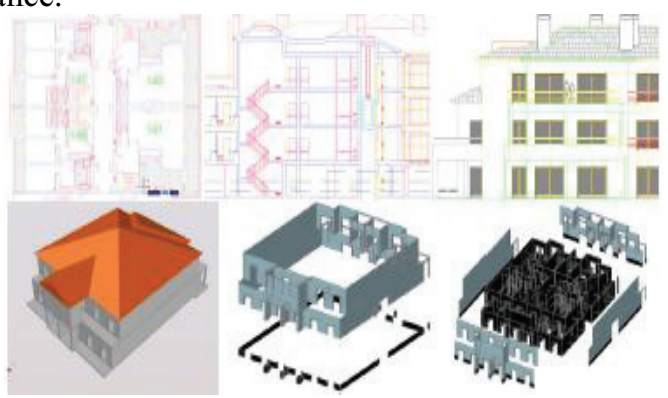

Fig. 6.Steps in the geometric modeling process.

All coatings studied were considered in this case-study. Thus the main façade was assumed to be tiled and the remaining façades painted while hall façades are of natural stone. Fig. 7 shows how to identify a façade in the virtual model of the building. Fig. 8 shows the inspection report of an anomaly.

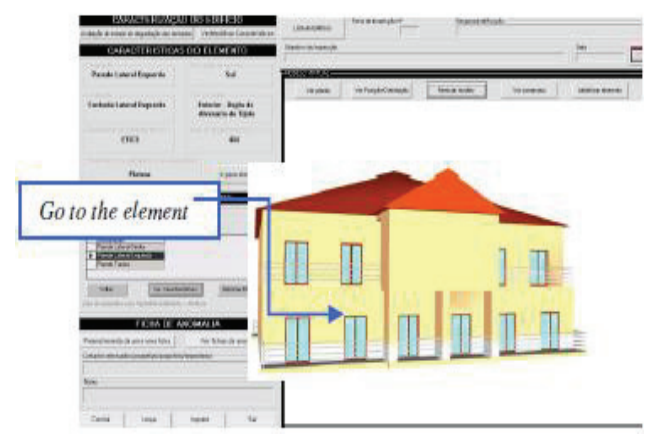

Fig. 7.Identification of a façade element.

The 3D model linked to a data base concerning maintenance produces a collaborative virtual environment, that is, one that can be manipulated by partners interested in creating, transforming and analyzing data in order to obtain results and to make decisions. For example, inspection reports can be definedand consulted by different collaborators. The process of developing the prototype interface considers these purposes. 


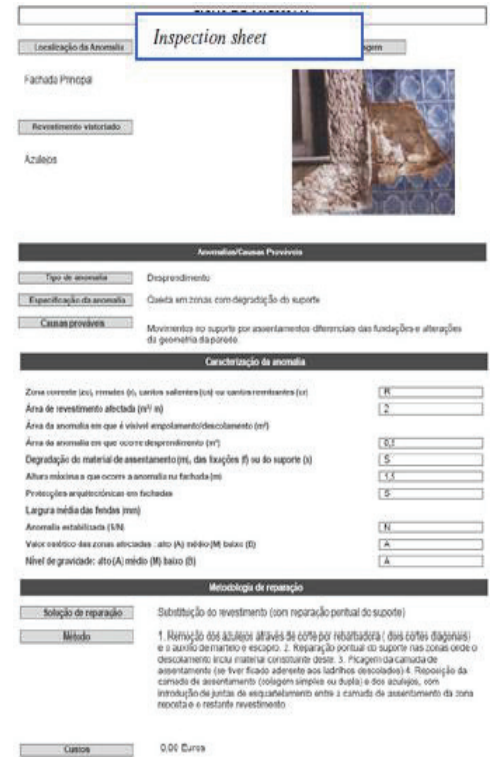

Fig. 8.An inspection sheet report.

The developed prototype associates the characteristics of thecoating component of the exterior walls to activities concerning the maintenance of buildings. One of the most important benefits of using this VR model concerns the help that the database access through the model can bring. The model can also support education namely in construction process classes.

\section{THE INTERIOR WALLS MAINTENANCE MODEL}

An identical analysis of the characteristics, anomalies and repair works concerning the interior finish materials was carried out [4]. With this information a data base was created. Another inspection interface was defined for the painted surfaces of interior walls, also associated to repair solutions and corresponding methodologies of rehabilitation (Fig. 9).

In addition the model identifies the period of time between the application of new paint and the predicted time when the next paint will be needed. The color changes between white (new) and red (when an area needs to be painted again). The data of periodic on-site inspections included in preventive maintenance is taken into account for each monitored element of the interior wall (Fig. 10).

Thus, when the date of interaction with the prototype is compared with the date predicted for the new paint application, the correspondent RGB (red, green and blue) values are calculated. Different RGB values generate different color, using this virtual model. Therefore, by using data visualization supported by this VR technology, it is possible to estimate if the wall needs painting immediately or not. This model is also available to be used in the inspection activity.

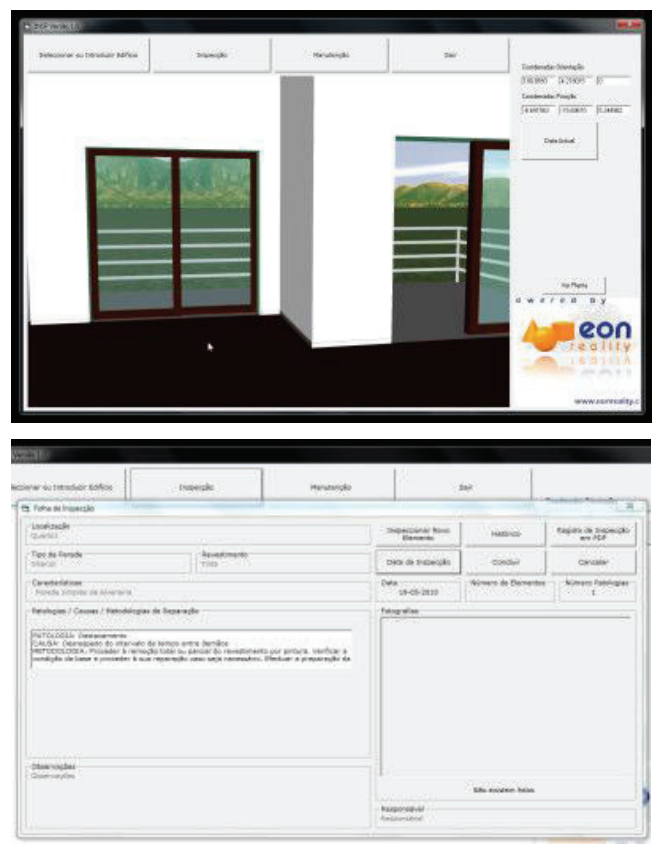

Fig. 9. Painted coating of interior walls, the inspection interface and changing color.

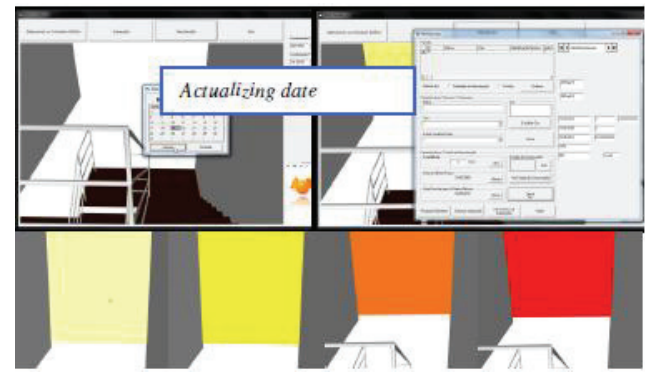

Fig. 10. Changing colors related to the maintenance of the painted interior wall.

\section{THE CONSTRUCTION PLANNING MODEL}

Construction management can be defined as the planning, co-ordination and control of a project from conception to completion (including commissioning) on behalf of a client [14]. This requires the identification of the client's objectives in terms of usage, function, quality, time and cost, and the establishment of relationships between the people involved, integrating, monitoring and controlling the contributors to the project and their output, and evaluating and selecting alternative solutions in pursuit of the client's satisfaction with the outcome of the project. It is essential, therefore, that the project designer has the depth of knowledge to be able to correctly identify the different stages of the construction planning, as well as to take into consideration the logistics and resources involved in the project. The construction planning used in the implemented prototype is realistic and considers the graphic 
and written documentation, measurements and quantities map, specifications and regulations relevant to the project [15].

A prototype based on VR technology with application to these demands of construction planning, was created. This interactive virtual model presents the project in $3 \mathrm{D}$, integrated with the construction planning schedule, resulting in a valuable asset in monitoring the development of the construction activity, compared to the construction planning already drawn up. The 4D application allows the time factor to be considered in conjunction with the 3D geometry of the different steps of the construction activity, according to the schedule established for the construction, thus offering a detailed analysis of the construction project. Additionally, VR technology allows the visualization of different stages of the construction and interaction with the real-time construction activity. This application clearly shows the constructive process, avoiding inaccuracies and building errors, thereby facilitating better communication between partners in the construction process. This application was developed in three stages: planning, modeling, and the integration of the first two stages.

- Planning takes into consideration the final purpose of thepresentation, and the definition of tasks; the details, therefore have to be in line with this idea. Using MicrosoftProject 2007, the tasks are introduced and the relations between them defined;

- Geometric modeling needs to relate correctly to the tasks as defined at the planning stage. Using AutoCAD 2010 as a modeling tool, the layers make the distinction between the different tasks and elements are created in enough detail to support correct comprehension. The application also presents a real-time illustration of the evolution of the construction through photographs of the site, taken at specific points in time;

- The third stage, integration, makes use of two programs. EON Studio 5.0 and Microsoft Visual C\# 2008 ExpressEdition, where the first takes the 3D model created with AutoCAD and introduces it in the application developed using the second.

\subsection{The interface}

The application, developed in C\#, integrates all the components described with the interface as shown inFig. 11. The application his organized as outlined below: Virtual model; Pictures of construction site; Planning task list; Gantt map.

The interaction with the application is made through Planning task list and Gantt map. Both the task list items and Gantt map bars are buttons which, when pressed, send the information to the EON for the task selected, and in return $E O N$ presents the model in the current state, that is, it shows and hides specific elements depending on the specific stage of the construction.

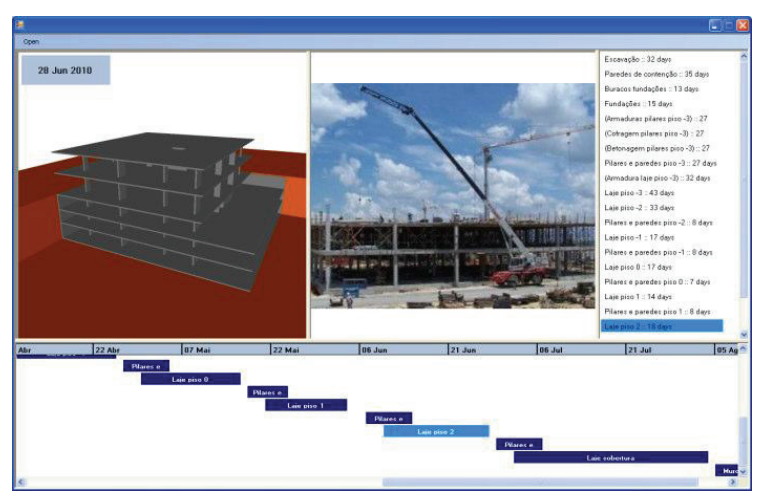

Fig. 11.Application interface.

$E O N$ can interact with the model in a number of different ways. In this prototype only the state of the elements and camera position is changed. The state of an element is presented by its Hidden property, whether it is selected or not, whilst the camera position is determined by translation and rotation coordinates. EON Studio also offers the possibility of changing the material associated with each element, creating a more realistic model.

Any new objects can be introduced into the application, just by modeling the new elements considering their positions relative to the ones already in the simulation and programming the associated action in EON Studio.

Likewise, the application accepts any kind of construction project, as long as its implementation imperatives are met. Additionally, with the appropriate models, it can also be used in construction site management.

\subsection{Programming details}

The weakness of this prototype lies in the time needed to carry out the preparation for the actual interaction with the application. Modeling a building may not be very extensive. The programming of the actions in EON Studio, however, canbe time-consuming.

In the application, the geometric model of the building is presented in a sequence simulating the construction activity. For that, each modeled component of the building is connected to the programming instruction: hidden and unhidden (Fig. 12).
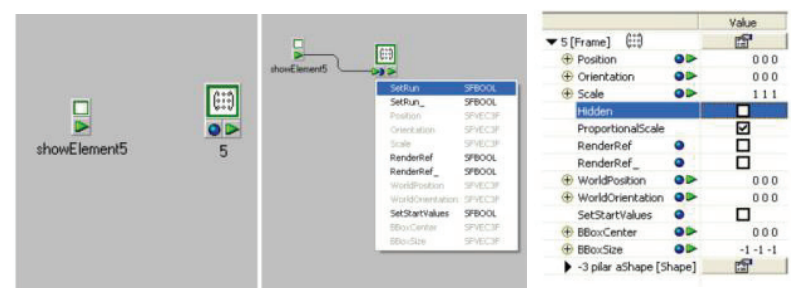

Fig. 12. Hidden and unhidden instruction

This is one of the capacities allowed by the EON software. The command of unhide is linked to each step (label of the list of activities and bar of the Gant map) and to each geometric 
model. The identification both in the list/map and the related geometric model is established by a number. The number corresponds tothe sequence defined in the design project. An action will beginwhen the user click over a label or a bar.

Fig. 13 presents a tree of links connecting the command of interaction (executed by the user) and the instruction show of the respective element (see the instruction showelement $n$ linked to the geometric model identified by the $n$ number).

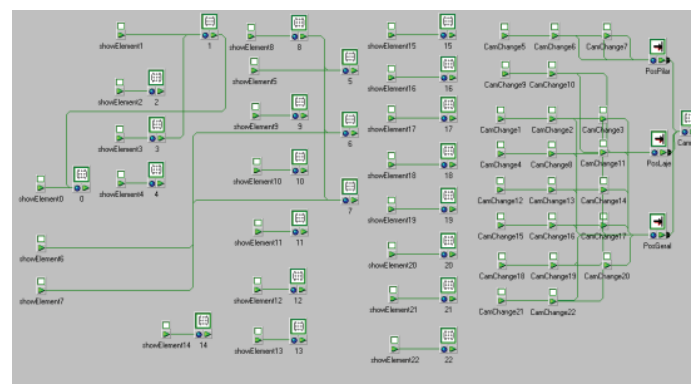

Fig. 13.Diagram of actions hidden and unhidden for each element and the control of the camera.

In addition the control of the position and orientation of a camera (position, zoom and orientation of the model in relation to the observer) must be defined in accordance with the selected construction step. The position of the camera is controlled within the EON software as shown in Fig. 13. A first position of the camera is defined in order to allow the user to visualize adequately the selected detail of the building (Fig. 14). After that the user is free to walkthrough inside and around the model. For that the user must interact with the 3D model through the VR window of the interface.
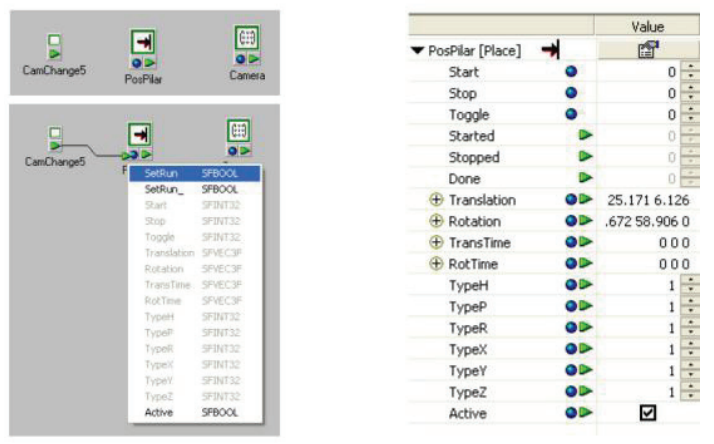

Fig. 14.Control of the translation and rotation movements of the model.

\subsection{The case study}

As a method of testing the application, a construction project was undertaken, more particularly, the structure of a building, using both its graphic documentation, that is, the architectural and structural blueprints, and the project description and construction planning (Fig. 15). The whole project was simplified to serve this paper's academic purposes: the list of tasks was defined based on the more characteristic stages of a construction process, and a few tasks focused on the construction details of certain elements.

As a result, AutoCAD layers were created for each taskdefined and the 3D model constructed. When finished, the 3Dmodel was exported to EON Studio, where a diagram of eventswas created, after which the application was ready to be used.

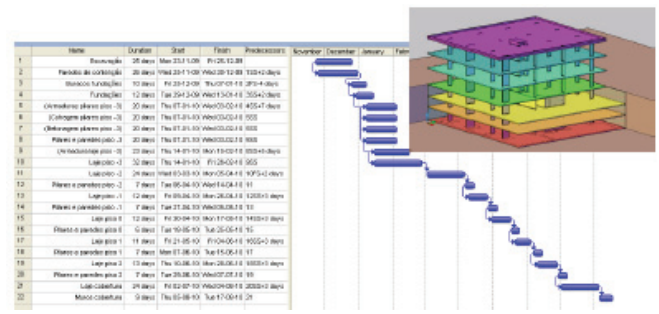

Fig. 15. Construction planning (list and Gantt map) and the 3D model of thebuilding structure.

As explained above, the task list and the virtual model are connected: when selecting a task, the relevant construction stageis presented (Fig. 16).
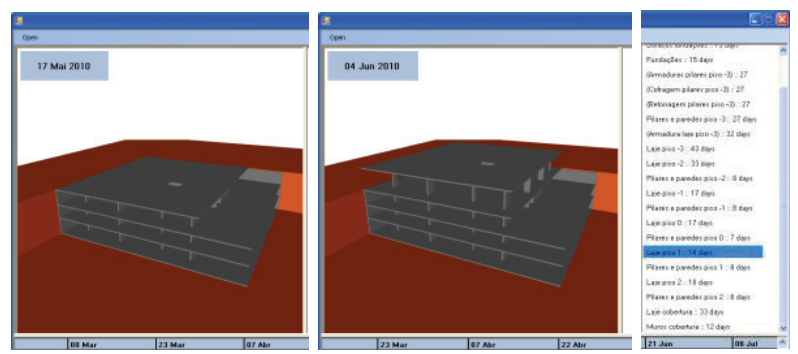

Fig. 16.Application's virtual model and task list

The first scenario is the landscape and then the foundationwork is shown (Fig. 17). There being no picture associated, thecamera symbol becomes visible instead.

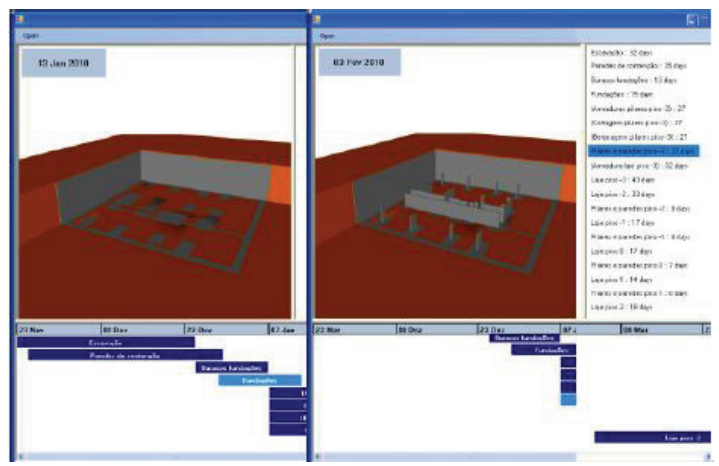

Fig. 17.Visualization of the foundation work.

Some construction details have been modeled. Progressacross three different stages, of one of the columns, is shown 
inFig. 18. A detail of the reinforcement and concrete of a slab isshown in Fig. 19.

When constructing a building, the planning sometimes needsto be changed due to unexpected occurrences. Implementingthese changes in the prototype is actually very simple, as theuser has only attribute new start and finishes dates to the task in MS Project and load the new file into the application.

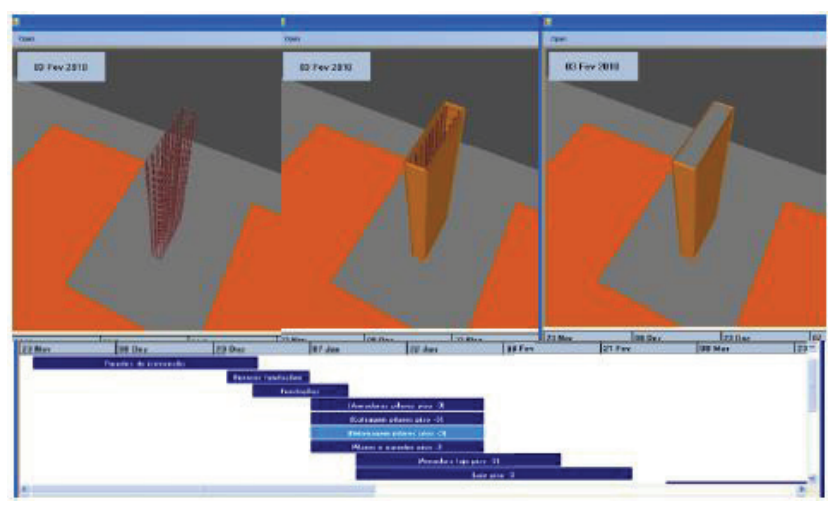

Fig. 18. Column construction: reinforcement, formwork and concreting.

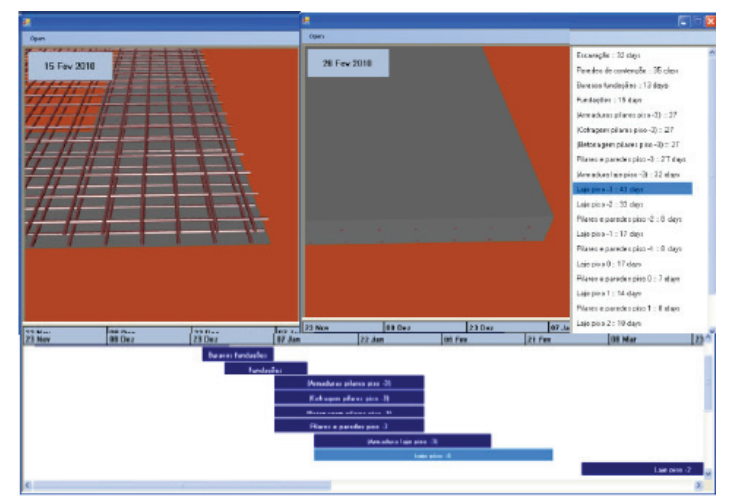

Fig. 19.Construction of a slab.

All steps have been modeled and linked to the planning chart. Fig. 20 shows the details of the construction work. The date for each visualized task is shown in the upper left corner of the virtual model window.

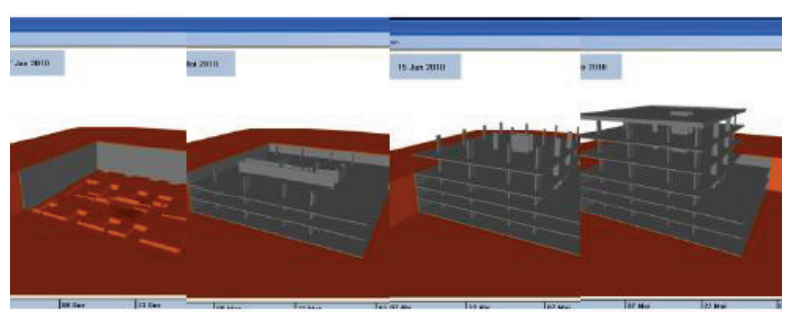

Fig. 20.Sequence of the construction process.

When a task is selected in the construction planning chart the static position of the model is presented. A first view is always linked to a task. This was established to provide easier interaction with the 3D model, and to focus the attention of the user on the important sections of each task, guiding them through the proper course of development of the construction.

Next, the user can manipulate the virtual model, in order to choose the identical perspective as that shown in the photo. So, with the visualization of what is planned and what has been done in the real building, the construction work can be better compared and analyzed (Fig. 21).

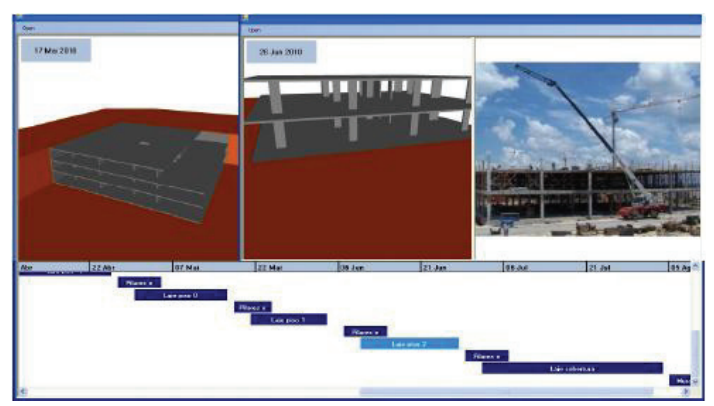

Fig. 21. Rotation applied to the virtual model.

In addition by manipulating the model the user can walk through the virtual building observing any construction detail he wants to compare. Comparing with other 4D models the interaction with the present model is not completed allowed and the pictures obtain in the construction place are not linked with the model [16]. So this VR model is more intuitive. So the principal innovative contribution of the model is the incorporation of updated pictures taken in situ. It helps designer to follow adequately the construction process and he can introduce the necessary changes in the construction plan previously established.

\section{CONCLUSIONS}

Virtual Reality technology with its capability of interaction and connectivity between elements was employed in the developed prototypes within a research project, offering several benefits both in presenting and developing projects and in supporting decision-making in the maintenance domain.

A VR model to support the maintenance of walls enables thevisual and interactive transmission of information related to the physical behaveour of the elements. The model shows the characteristics of each element of the building in the model and the information related to inspection, anomalies and repair works. As the $3 \mathrm{D}$ model is linked to a database in an interactive environment and has a user-friendly interface with easily manipulation of the data, it engenders a collaborative system. With this application, the user may fully interact with the program referring to the virtual model at any stage of the maintenance process and can analyse the best solution for repair work. It can also support the planning of maintenance strategies. The developed software is easy to handle and transport for on-site 
inspections and comprises information of the causes, solutions and methods for repairing anomalies.

Technical drawings and explanatory texts often have little detail and are frequently insufficient in fully comprehending the object. Using VR models means that mistakes can more easily be caught before construction starts, which translates into time and cost reduction. The construction planning model can be used with any kind of construction project and, being a flexible application, accepts new data when necessary, allowing for a comparison between the planned and the constructed. The prototype can also be expanded to include other aspects of construction management, such as resource administration, or to have real-time access to the construction, through the use of cameras installed on site. The use of new mobile technologies could move the application to the construction site, clarifying any doubts about location or position of each component.

Both models support construction activity. The VR construction model allows the presentation of each step comparing what is planned with the real situation observed, the pictures taken in situ. The model, therefore, helps the designer and owner to redefine the early plan introducing changes to the work in progress. Thus, economic benefits of updating the planning schedule are achieved along with better, error-free construction with no unnecessary delays. The maintenance model supports the global analysis of the need for repair tasks in a building, helping the designer to define an adequate plan of rehabilitation work. The plan must incorporate the repair of all anomalies detected during an inspection visit, which are reported, with the help of the VR model, it, too, bringing economic benefits.

Two other VR models are now in progress, concerning the inspection activity of floors and roofs of buildings. With these two other modules the research project will be complete. Then the complete VR application will support different aspects ofthe maintenance process in buildings.

\section{ACKNOWLEDGMENT}

The authors gratefully acknowledge the financial support of the Foundation for Science and Technology, a Governmental Organization for the research project PTDC/ ECM/67748/ 2006, Virtual Reality technology applied as a support tool to the planning of construction maintenance, now in progress.

\section{REFERENCES}

[1] A. Z. Sampaio, M. M. Ferreira and D. P. Rosário. Interactive virtual application on building maintenance: The lighting component, In Proc. IRF2009, 3rd International Conference on Integrity, Reliability and Failure: Challenges and Opportunities, Symposium Visualization and human-Computer Interaction, Oporto, Portugal, abstract pp. 221-222, paper 11 pgs., July 2009.

[2] J. P. Santos. Construction Planning using 4D Virtual Models, Integrate Master Degree Thesis in Construction, Technical University of Lisbon, Portugal, 2010.

[3] A. R. Gomes. Virtual Reality technology applied to the maintenance of façades, Integrated Master Degree Thesis in Construction, Technical University of Lisbon, Portugal, 2010.

[4] D. P. Rosário. Maintenance planning of the closure of interior walls supported on virtual environment, Integrated Master Degree Thesis in Construction, Technical University of Lisbon, Portugal, 2011.
[5] E. H. Mohammed. n-D Virtual Environment in Construction Education, In Proc. ICVL 2007, the 2nd International Conference on Virtual Learning, pp. 1-6, 2007.

[6] A. Z. Sampaio and P. S. Ferreira. Virtual Reality Models Used in Civil Engineering, In Proc. IMSA'06 - the 24th IASTED international conference on Internet and multimedia systems and applications Education, CA, USA, USA. 2006 [http://portal.acm.org/citation.cfm?id=1169188].

[7] A. Z. Sampaio, M. M. Ferreira, D. P. Rosário and O. P. Martins. 3D and VR models in Civil Engineering education: Construction, rehabilitation and maintenance, Automation in Construction 19 (2010), 819-828.

[8] S. Yerrapathruni, J. I. Messner, A. J. Baratta and M. J. Horman. Using 4D $\mathrm{CAD}$ and Immersive Virtual Environments to Improve Construction Planning, In Proc. CONVR 2003, Conference on Construction Applications of Virtual Reality, Blacksburg, VA, pp. 179-192, 2003.

[9] R. M. Webb and T. C. Haupt. The Potential of 4D CAD as a Tool for Construction Management, In Proc. $7^{a}$ Int. Conf. on Construction Application of Virtual Reality, USA, 2003.

[10] A. M. Gomes and A. P. Pinto. Didactic text of construction materials, Technical University of Lisbon, IST, Lisbon, Portugal, 2009.

[11] L. Ferreira, J. Coroado, V. Freitas and I. Maguregui. Causes of the fall of tiles applied to exteriors of buildings. Patterned tiling in buildings from 1850-1920. In Conf. Patorreb, 3rd Meeting on Pathology and rehabilitation of Buildings, FEUP, Oporto, Portugal, March 2009.

[12] M. Veiga and S. Malanho. Natural stone coating: methodology of diagnosis and repair of anomalies. In Conf. Patorreb 3rd Meeting on Pathology and Rehabilitation of Buildings, FEUP, Oporto, Portugal, March 2009.

[13] EON Studio Introduction to working in EON Studio, EON Reality, Inc. (2010). [http://www.eonreality.com/]

[14] A. Walker. Project Management in Construction, Fourth edition, Oxford, Blachweel Publishing, 2002.

[15] J. Leinonen, K. Kähkönen and A. Retik. New construction management practice based on the virtual reality technology, in book $4 D C A D$ and Visualization in Construction: Developments and Applications, (Eds.) R. A. Raja, Ian Flood Issa, J. William O’Brien. A.A. Balkema Publishers, pp. 75-100. 2003.

[16] J. Casimiro. Integrated Planning of Deadlines and Costs in PME's Small and Medium Businesses, Integrated Master Degree Thesis in Construction, Technical University of Lisbon, Portugal, 2006.

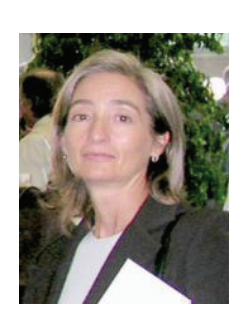

Alcínia Z. Sampaio, Assistant Professor at the Technical University of Lisbon (TULisbon), in the Department of Civil Engineering, $\mathrm{PhD}$ in Civil Engineering by TU Lisbon, since 1999, MSc in Structures Engineering by TU Lisbon, since 1989, and BSc in Civil Engineering by TU Lisbon, since 1983.

She teaches Technical Drawing since 1984 and Computer Added Drawing since 2003 for Civil Engineering students. She has organized short courses in Nov. 2010, Introduction to Virtual Reality Technology applied on architecture and Engineering, TU Lisbon and in Feb. 2009, Automatic generation of drawing using DXF files, TU Lisbon.

The main research fields are Geometric modeling and virtual reality applied to construction. She ismember of Institute of Constructionat the TU Lisbon. She has supervised the researcher project Automatically generating model of bridges graphic representation, (2001-2004) and has collaborated with the projects Virtual reality in optimization of construction project planning, (2001-2004). Also has developed didactic models to support engineering education Actually she is the principal researcher of the project Virtual Reality Technology applied as a support tool to the planning of construction maintenance, (2008-2011).

https://fenix.ist.utl.pt/homepage/ist12448

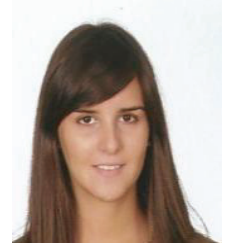

Ana R. Gomes, Civil Engineering, MSc in Construction Engineering by TU Lisbon, since2010, and BSc in Civil Engineering by TU Lisbon, since 2009.

The main research fields are Geometric modeling and virtual reality applied to construction. She was a fellowship of the project Virtual Reality Technology applied as a support tool to the planning of construction maintenance, (2008-2011). 


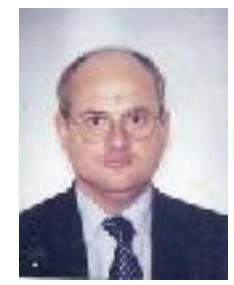

Augusto M. Gomes Associate Professor at the Technical University of Lisbon (TULisbon), in the Department of Civil Engineering, $\mathrm{PhD}$ in Civil Engineering by TU Lisbon, since 1992, MSc in Structures Engineering by TU Lisbon, since 1987, and BSc in Civil Engineering by TU Lisbon, since 1983 .

He teaches Construction Materials, Materials in Structures, Protection, Repair and Strengthening Materials since 1984 for Civil Engineering students. Hismember of Institute of Constructionat the TU Lisbon He teaches advanced course in Structure and Behavior of Construction Materials, Construction Materials, TU Lisbon.

The main research fields are Construction Materials, Technology and Management Innovation: advanced materials (GFRP, CFRP, GRC); waterproofing systems; concrete and mortars. Actually he is a researcher member of the project Virtual Reality Technology applied as a support tool to the planning of construction maintenance, (2008-2011).

https://fenix.ist.utl.pt/homepage/ist12113

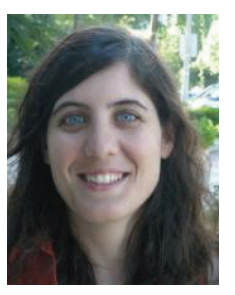

Joana P. Santos, Civil Engineering, MSc in Structures Engineering by TU Lisbon, since2010, and BSc in Civil Engineering by TU Lisbon, since 2009.

The main research fields are Geometric modeling and virtual reality applied to construction. She was a fellowship of the project Virtual Reality Technology applied as a support tool to the planning of construction maintenance, (2008-2011).https://fenix.ist.utl.pt/home page/ist 153540

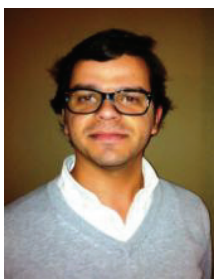

Daniel P. Rosário, Civil Engineering, MSc in Construction Engineering by TU Lisbon, since2011, and BSc in Civil Engineering by TU Lisbon, since 2009.

The main research fields are Geometric modeling and virtual reality applied to construction. He was a fellowship of the project Virtual Reality Technology applied as a support tool to the planning of construction maintenance, (2008-2011). 